\title{
Small-scale surface streaming under natural conditions as effective in air-sea gas exchange
}

\author{
By J. GEMMRICH* and L. HASSE, Institut für Meereskunde, Düsternbrooker Weg 20, D-2300 Kiel, \\ Germany
}

(Manuscript received 14 March 1991; in final form 23 December 1991)

\begin{abstract}
A series of field experiments has been made to determine the occurrence of small-scale surface motions that might enhance gas exchange by surface renewal. Out of 93 runs under natural conditions on open bodies of water, only 19 gave no indication of surface streaming within a few seconds. The data cover the wind speed range up to about $6 \mathrm{~ms}^{-1}$. Above 2 or $3 \mathrm{~ms}^{-1}$, predominately line structures were observed. This points to an important rôle of surface renewal in gas exchange.
\end{abstract}

\section{Introduction}

Nearly 50 years ago, Woodcock (1941) reported on an experiment to study surface motions at the water surface. The title of his paper "Surface cooling and streaming in shallow salt and fresh waters" indicates what he observed. There were surface water movements that formed lines and streaks fast enough that the eye was not really able to determine details of the motions. His experiment, being conducted during clear nights in a shallow fresh water pond, was designed to reveal convectively driven motions. However, in the very lively description of the different characteristics of movements that he observed, Woodcock included: "when winds are blowing, there is invariably found a small scale streaming... ...in lines roughly parallel to the wind direction. The streams are usually about a centimeter across". Such secondary motions of a scale of a few $\mathrm{cm}$ may be taken as indication of surface renewal. Here, we see a connection to present research interests: gas exchange at the sea surface is of great interest in the debate on manmade climate change. The uptake of $\mathrm{CO}_{2}$ by the ocean may significantly reduce the impact on the greenhouse effect of man's production of

* Present affiliation: Institute of Ocean Sciences, P.O. Box 6000, Sidney, B.C., V8L 4B2, Canada. carbon dioxide from burning of fossil fuel. The sea surface proper at open sea is nearly inaccessible to experimental determination of gas exchange. Considerable effort is necessary even to achieve laboratory measurements (e.g., Asher and Pankow, 1991). However, for a global application parametrisations are necessary that should be based on a sound physical model. Unfortunately, the two major models yield gas fluxes different by a factor of two (see, e.g., Deacon 1977, Holmén and Liss, 1984, Hasse 1990). While the boundary layer model explains fluxes through the interface by the additive action of molecular and turbulent transports (e.g., Kitaigorodskii, 1984; Coantic, 1986) the surface renewal model postulates a mechanism to renew the fluid at the interface in order to accelerate the rather ineffective exchange of gas by molecular action. Hence, in order to accept the model of surface renewal one would need to identify such secondary motions at the open ocean, and under what conditions these prevail.

It is regrettable that after the early observations of surface streaming by Woodcock, the interest in small-scale ocean surface motions had declined again. Some attention has been given to Langmuir circulations that are ordered secondary flows but of considerably larger scale (e.g., Langmuir, 1938; Krauss, 1965). Because of their scale of order 10 to $50 \mathrm{~m}$ or more these are not suitable to enhance gas exchange. Apparently, the experiments of 
Woodcock have not been repeated. We have therefore started a series of simple field experiments to see whether and under what conditions surface streaming or other secondary motions occur. The intention of our work was a pilot study, we did not try to make a complete investigation. In the present paper we report on our experiments. We may mention here that we were specifically looking for secondary motions that could exchange water between the surface proper and the bulk of water at, say, a few cm depth.

When a field experiment is devised, one usually has some conceptions what processes might be expected. In our case, we presumed to find secondary motions from the same type, but smaller scale, as are known to occur in the atmospheric boundary layer: convectively driven motions in forms of cellular convection ("hexagonal" cells) or helicoidal motions that in the atmosphere become visible through cloud streets and that may be conceived as result of concerted action of convection and wind. We are aware that at the sea surface there is wave breaking too. The Beaufort scale of wind speed in fact is based on visible characteristics of wave breaking. The frequency of breaking waves, that produces visible traces in form of white caps, has been studied by other researchers (e.g., Monahan and MacNiocaill, 1986). At moderate wind speeds, wave breaking with white caps is rare and probably not the dominating feature in surface renewal. Hence, we did not study white cap structure in the present context. However, microscale breaking (see Phillips, 1977) could produce secondary motions. Such secondary motions when present are included in our observations.

\section{Experimental procedure}

Woodcock used lycopodium spores thrown by hand onto the sea surface to make surface motions visible. We too used lycopodium in the beginning, but found powdered corkwood less expensive and equally well suited for our purpose. The powder was thrown manually; surface patterns were recorded by a video camera. The size of visible structures was measured by reference to a $1 \mathrm{~m} \times 1 \mathrm{~m}$ floating frame. In order to minimize interference of the frame with the surface motion, the frame rested on four submerged buoyancy volumes of about $10 \mathrm{~cm}$ scale with only 4 slim rods piercing through the surface. The velocity of secondary motions was estimated from the time elapsed between video frames. Spatial scale of structures was measured from projected single frame pictures with due correction for distortion by oblique viewing.

Measurements were taken at different sites at the Kieler Förde, from a jetty at Kiel lighthouse,

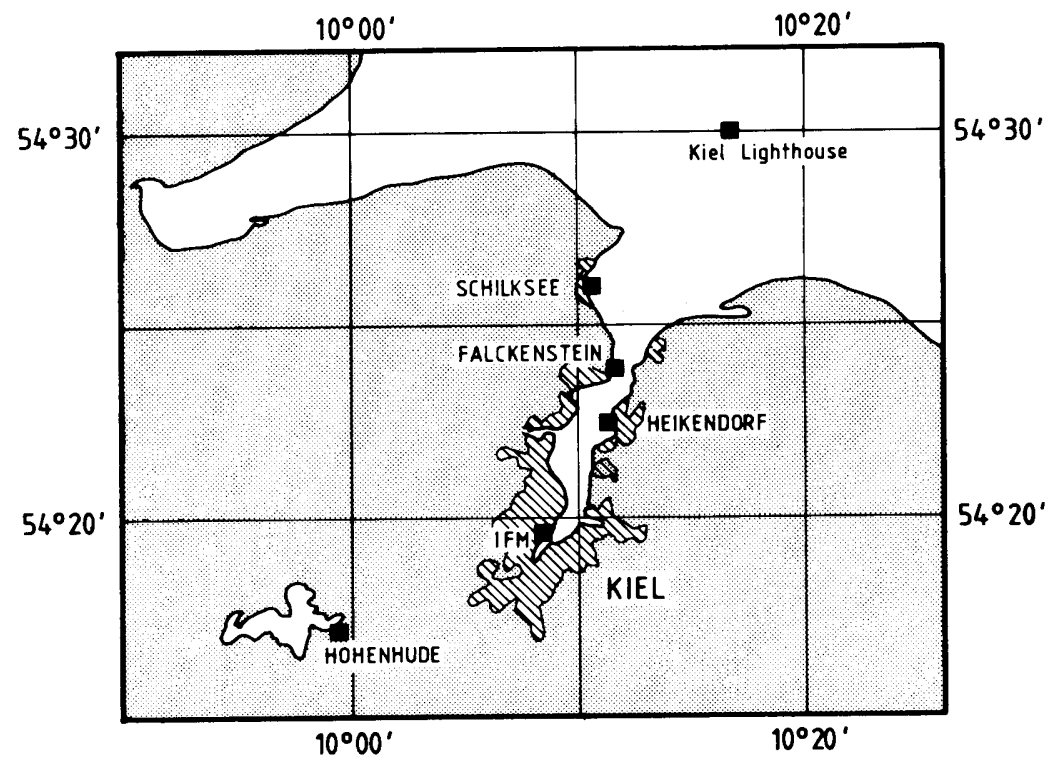

Fig. 1. Sites of observations. 
and a nearby lake (see Fig. 1 for locations). The typical site is a wooden boat landing about $1 \mathrm{~m}$ above the water, resting on poles of about $0.5 \mathrm{~m}$ diameter. Only one series of 3 runs has been made from the concrete jetty of Kiel lighthouse (15 Nov. 1989). The runs showed stripes; though the wind was parallel to the jetty, no wavelengths were determined because of possible reflection of waves. The other 10 runs at the Kiel lighthouse site were taken from an isolated mast of $20 \mathrm{~cm}$ diameter, at about $300 \mathrm{~m}$ distance from the lighthouse. Environmental conditions were recorded at the roof of Institut für Meereskunde and at the Kiel lighthouse. Additionally, the local wind speed was taken with a portable averaging anemometer at the site of each experiment at heights varying from $2 \mathrm{~m}$ to $6 \mathrm{~m}$ above water depending on local structures. More details are given in Gemmrich (1990).

\section{Theoretical background}

In the experiment, we searched for surface streaming as indication of surface renewal that could enhance gas exchange through the air sea interface. Because of the ineffective molecular transport in the viscous sublayer at the aqueous side of the interface, this sublayer is the bottle neck for such gases that are not highly soluble. Compared to the boundary layer theory, where molecular and turbulent transport are assumed to add (e.g., Deacon, 1977) surface renewal would enhance gas exchange by bringing repeatedly water from the bulk to the surface, thus increasing the driving gradient in the interfacial layer. However, surface renewal would be effective only if it occurs often enough to really increase the average gradient compared to the equilibrium profile. The surface renewal theory (e.g., Liu and Businger, 1975) contains an empirical coefficient, that may be interpreted as a renewal time or average lifetime that a fluid element remains at the surface. This lifetime can be estimated to be of order 10 seconds for typical open sea values of heat flux and surface minus bulk water temperature difference and moderate wind speed. This is in agreement with the experimental evidence (about 5 seconds) from artificially disturbing the surface film (Ewing and McAlister, 1960). Accordingly, we consider surface renewal with a time scale of order
10 seconds or less as favourable for enhancement of gas exchange.

Looking for environmental conditions of smallscale secondary motions, it is natural to suspect wind and buoyancy as driving forces. What are the relevant scales or dimensionless numbers for these forces? For wind driven motions, we would use either wind speed (at $10 \mathrm{~m}$ height, say) itself, or friction velocity. We have not explicitly included wave characteristics in our experiment. Anyhow, waves and perhaps micro-scale breaking are implicitly covered since most of our runs are with light winds, where waves are very soon near equilibrium and are described well in terms of wind speed.

For buoyancy, the temperature difference $\Delta \mathrm{T}$ between surface and bulk water, and the corresponding density difference, will be the primary characteristic variable. In case of convective motions, this is often cast in form of a RayleighNumber Ra (e.g., Busse, 1989). However, it is difficult to take a Rayleigh-number as governing variable in this type of problem, since Ra contains the depth of the layer to third power. The typical situation for $\mathrm{Ra}$ is a layer of given depth, where continuous differential heating/cooling produces buoyantly driven motions, that reach an equilibrium through heat conduction and energy dissipation. In the present type of problem, there is no externally prescribed depth of the layer.

We have tested the idea, that the relevant depth to be used with $R a$ is the depth of the equivalent layer thickness, defined as the depth where the mean temperature profile indicates the change from viscous to turbulent type of profile, based on the Reichardt profile (see Hasse (1971)). Since this test was not very successful, the results will not be detailed here.

Contrastingly, we may suppose that the depth of the layer where buoyantly driven motions dominate the transports is an inner variable of the problem. In this case this depth scale is likely to be determined by a (constant) critical Rayleigh number.

We therefore need to look for other variables characterising buoyancy as primary force. Naturally a relevant variable is the heat balance at the sea surface that could drive buoyant motions. The heat balance at the interface is composed of shortwave solar insolation and the heat exchange by net long wave radiation, evaporation and sensible heat transfer. The latter three are conducive 
to buoyantly driven secondary motions since these provide, except in rare conditions, for a heat loss of the ocean.

The different physics of energy transport near the interface by shortwave radiation and molecular conduction precludes to simply take the total radiative and turbulent energy exchange at the sea surface as a governing parameter. Since back radiation, sensible and latent heat exchange originate at the interface the ocean has to sustain the heat flux through turbulent and molecular action. Turbulence is restricted near the interface proper by surface tension (Hasse and Liss, 1980 ), therefore the heat flow at the interface is dominated by molecular transport, and strong temperature gradients are found at the interface. On the other hand, solar radiation penetrates the sea surface with an extinction-coefficient that is wavelength dependent (see, e.g., Schmidt (1908) or oceanography text books). Visible light penetrates to a depth of some meters while the IR part of solar radiation is absorbed within the upper millimeter to decimeter. This absorption of solar radiation near the sea surface results in a temperature decrease with depth and a stable stratification.

When the sun is high, the insolation can be much larger than the heat loss at the interface. On the other hand, the thickness of the layer with molecular transport of heat in the water is of $\mathrm{mm}$ order. At this depth, about $15 \%$ or $20 \%$ of the solar radiation only is absorbed. Hence, even with moderate or high insolation, the absorption in the uppermost layer may not be sufficient to compensate the heat loss. A temperature profile may result where near the interface the heat flux is upwards until at some depth the absorbed fraction of insolation exceeds the heat loss and the heat flux is downward below.

In order to have a relevant characteristic of buoyant forcing we have calculated an effective heat flux for the uppermost layer by considering only that fraction of shortwave radiation that is absorbed either above the maximum in the temperature profile, or above the change of gradient in the temperature profile that roughly indicates transition from molecular to predominately turbulent transport (see Fig. 2). Since the frequency dependence of absorption of solar radiation in water is quite strong, the amount absorbed in the uppermost layer is not very dependent on its exact depth. Hence, the shortwave insolation can be (a)

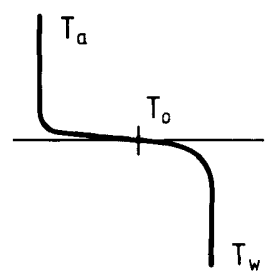

(c)

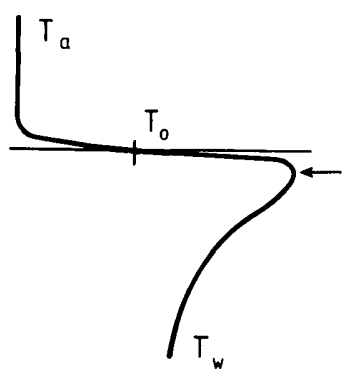

(b)

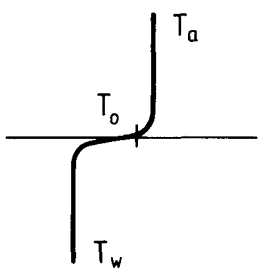

(d)

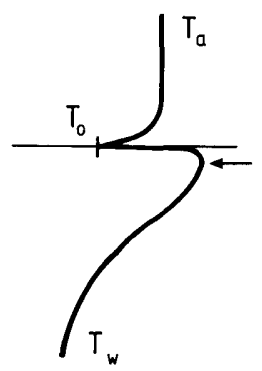

Fig. 2. Schematic temperature profiles. $T_{\mathrm{a}}, T_{\mathrm{w}}, T_{\mathrm{o}}$ indicate bulk air temperature, bulk water temperature, and water temperature at the interface, respectively. The arrow indicates depth of layer, that has been used to calculate absorption for determination of an effective heat flux. Situations $\mathrm{a}, \mathrm{b}$ are without, $\mathrm{c}, \mathrm{d}$ with solar radiation.

reduced with a gross factor of 0.15 to roughly determine the amount absorbed in the uppermost layer.

The preceeding discussion showed that the action of different processes at the interface and the interfacial layers of the ocean make the conditions for secondary motions at the surface very complex. The driving forces may be mechanical (wind and waves) and buoyant (cooling from above and heating from below). Additionally, the depth of the unstable layer may vary in a complex way because of the different character of radiative and conductive heat transfer.

The problem of the relevant depth scale is an interesting one since an externally forced layer thickness may determine the type and scale of surface motions. Depending on magnitude and sign of the different components of the heat balance, different situations may develop. With solar radiation, the top layer may be unstable, while the 
stratification is stable below. Even with air temperature higher than bulk water temperature, there may be a very shallow layer of unstable stratification on top, when the heat loss by evaporation and IR radiation is vigorous enough.

Intuitively, we would infer from the observed surface patterns the existence of threedimensional motions in the form, say, of hexagonal cells or roll vortices. However, it is conceivable that with stable stratification a very thin surface film becomes decoupled from the deeper layers and is accelerated by wind force.

\section{Results}

In our experiments, the secondary surface motions are represented by the visible pattern of the marked surface (Fig. 3). The observations can be divided into descriptive categories as follows.

Lines. The tracer became organized in definitely isolated lines or stripes, i.e., between the lines no tracer remained. The lines need not be fully parallel, they may converge but their length is large compared to the distance between lines. This pattern covers all of the marked patch.

Marginal fingers. At the upwind and downwind side of the original marked patch the homogeneous field was broken up into lines or fingers.

Accelerated stripes. Within the marked patch narrow stripes developed in which the tracer moved much faster than in the space in between. At the edges, the movement resulted in fingers (as described above). This was counted separately because of the different pattern within the bulk of the field.

Fragments. This indicates that less than half of the marked patch showed structures or that the openings between lines were not free of marker.

Cells. These are cell-like structures as commonly described with convection. Here, too, open and closed cells were found.

No structures. The patch remained homogeneous for at least a few seconds indicating absence of secondary motions.

Within a particular situation, usually a number of runs were taken. From 93 runs 37 showed lines, 13 marginal fingers, 6 accelerated stripes, 4 cell structures, 12 fragments, 19 no structures, and 2 no recognizable pattern.
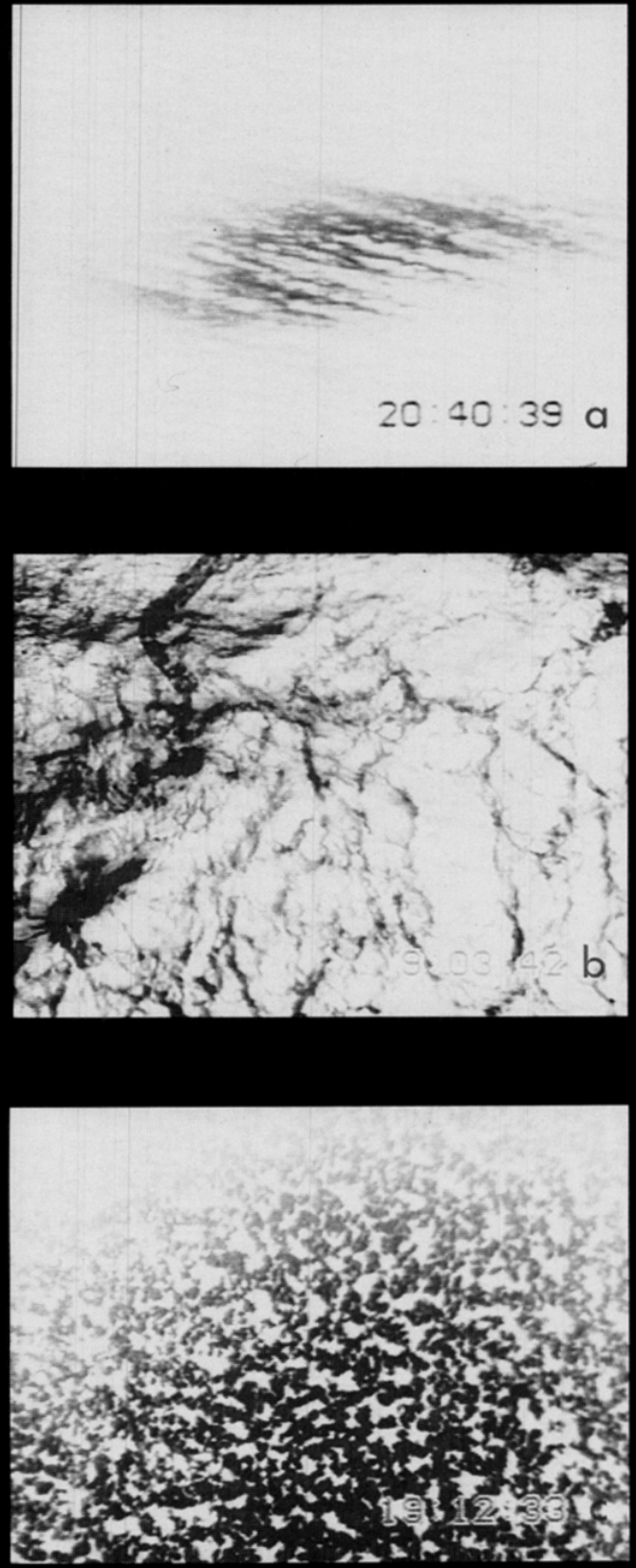

Fig. 3. Samples of observed patterns reproduced from video recordings. (a) lines, distance between lines is of order $30 \mathrm{~cm}$. (b) lines, possibly produced from wave breaking. Such patterns are not used for determination of wave length and time constants. Note that the visible white structures are from cork powder, not from bubbles. (c) cells. Diameter of the open cells is of order $1 \mathrm{~cm}$. 
It is understood that categorization of observations of motions into a few types can transfer only part of the observed details. Different processes at the sea surface may work simultaneously. For example, at low wind speed, the wind may increase shortly and die away again within fractions of minutes. Wind and wave directions may change and the wind blow at odd angles to the wave direction. For the interpretation of results it is interesting to note that the pattern of the marker, whence established, usually remained unchanged when a few smaller waves run through the marked patch. Occasionally, observations were obtained where waves that passed through the homogeneous patch produced patterns. These patterns remained for some time while several smaller waves run through it. Another wave than may disturb the pattern by collecting the marker and redistributing it into a new pattern on passing. The time from the first structuring until erasing and restructuring is of the order of a few $10 \mathrm{~s}$ or several wave periods. We think of these patterns as produced by microscale breaking though we can not prove that. These patterns are in the class "lines". Out of 37 observations of lines, 11 appear to be influenced by "breaking" waves. Though from several days, these observations are all in a fairly narrow range of windspeed $(3.5$ to $6 \mathrm{~m} / \mathrm{s})$ and stability ( -4 to $-7^{\circ} \mathrm{C}$ air-sea temperature difference) and exhibit no obvious peculiarities. We do not have observations with white caps.

On several occasions within a given day, it happened that patterns were observed that on decreasing wind speed disappeared. Wind speed

Table 1. Characteristics of observations of line structures

\begin{tabular}{|c|c|c|c|c|c|c|}
\hline \multirow[t]{2}{*}{ Run } & \multicolumn{2}{|c|}{ Length scale } & \multicolumn{2}{|c|}{ Velocity } & \multirow{2}{*}{$\begin{array}{c}\text { Time scale } \\
t^{*} \\
(\mathrm{~s})\end{array}$} & \multirow[t]{2}{*}{ Type } \\
\hline & $\begin{array}{c}L \\
(\mathrm{~cm})\end{array}$ & $\begin{array}{l}\text { s.d. } \\
(\mathrm{cm})\end{array}$ & $\begin{array}{c}v \\
(\mathrm{~cm} / \mathrm{s})\end{array}$ & $\begin{array}{c}\text { s.d. } \\
(\mathrm{cm} / \mathrm{s})\end{array}$ & & \\
\hline Sept. $20 \# 5$ & 1.4 & 0.4 & & & & \\
\hline Oct. 03 a.m. \#1 & 5.8 & 1.2 & 3.4 & 0.9 & 0.8 & A \\
\hline Oct. 03 a.m. \#2 & 5.1 & 0.5 & 2.0 & 0.7 & 1.3 & A \\
\hline Oct. 04 & 4.4 & 1.2 & 6.1 & 2.2 & 0.4 & B \\
\hline Oct. 05 a.m. \# 1 & 5.4 & 1.9 & 1.1 & 0.2 & 2.5 & A \\
\hline Oct. 05 p.m.\#1 & 4.9 & 0.6 & 5.4 & 1.0 & 0.4 & B \\
\hline Oct. 05 p.m. \#2 & 4.2 & 0.6 & & & & \\
\hline Oct. 06 \#2 & 5.2 & 0.7 & & & & \\
\hline Oct. $06 \# 4$ & 4.1 & 0.5 & & & & \\
\hline Oct. 10 \# 1 & 3.2 & 0.3 & 3.5 & 0.3 & 0.5 & B \\
\hline Oct. $10 \# 3$ & 3.3 & 0.6 & 1.8 & 0.9 & 0.9 & B \\
\hline Oct. $10 \# 4$ & 3.4 & 0.4 & & & & \\
\hline Oct. $10 \# 5$ & 3.7 & 1.3 & & & & \\
\hline Oct. 12 & 4.1 & 1.2 & 4.2 & 0.6 & 0.5 & B \\
\hline Oct. 30 & 6.6 & 0.5 & 4.6 & 1.2 & 0.7 & B \\
\hline Nov. 02 & 3.8 & 1.4 & 2.3 & 3.2 & 0.8 & B \\
\hline Nov. 09 \# 1 & 4.8 & 0.2 & & & & \\
\hline Nov. 09 \#2 & 6.7 & 0.1 & & & & \\
\hline Nov. 09 \# 3 & 6.3 & 0.2 & & & & \\
\hline Nov. 18 \#1 & 20.0 & 4.1 & & & & \\
\hline Nov. 18 \#2 & 35.0 & 4.3 & & & & \\
\hline Nov. 18 \#3 & 7.0 & 1.3 & & & & \\
\hline Nov. 24 \# 1 & 11.3 & 2.7 & 2.5 & 0.7 & 2.3 & A \\
\hline Dec. 04 \# 1 & 15.8 & 1.9 & 1.8 & 0.9 & 4.4 & B \\
\hline Dec. 04 \# 2 & 11.9 & 0.5 & & & & \\
\hline
\end{tabular}

The run number consists of the date (september through december 1989), a.m. or p.m. when more than one series per day was made, and the run count within each series. Length scale $L$, velocity $v$, and time scale $t^{*}$ are given as well as the corresponding standard deviations. Type of observation is indicated by A, B, where A stands for velocity from converging lines, $\mathrm{B}$ from generation of lines. 


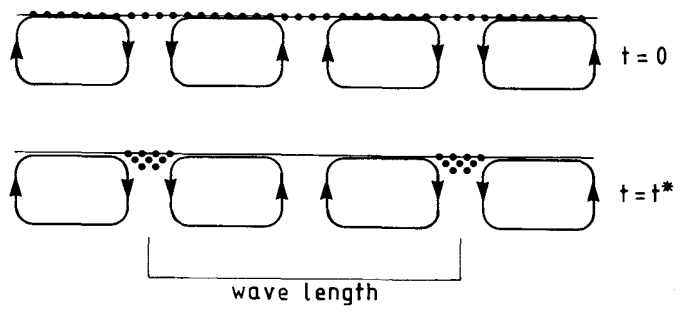

Fig. 4. Schematic of distribution of marker at time $t=0$ and $t=t^{*}$, and the inferred circulation pattern. Wave length scale refers to distance between line structures of marker at the surface.

for this decay was roughly about $3 \mathrm{~m} / \mathrm{s}$, but because of considerable scatter we have insufficient data to establish a "decay" wind speed.

The distance between lines defines a wavelength or length scale (Fig. 4). There are not enough observations of cell like structures to determine a diameter of cells, but those observed were roughly the same size as the "wavelength" of line structures, perhaps somewhat towards the smaller range. A velocity of the secondary motions could be determined by either observing the development of lines out of the homogeneously marked field, or from lines that drifted towards each other. For $25^{\prime}$ (out of the 93) runs it was possible to determine a wavelength and for 12 a velocity (see Table 1). Many of the runs showed individual

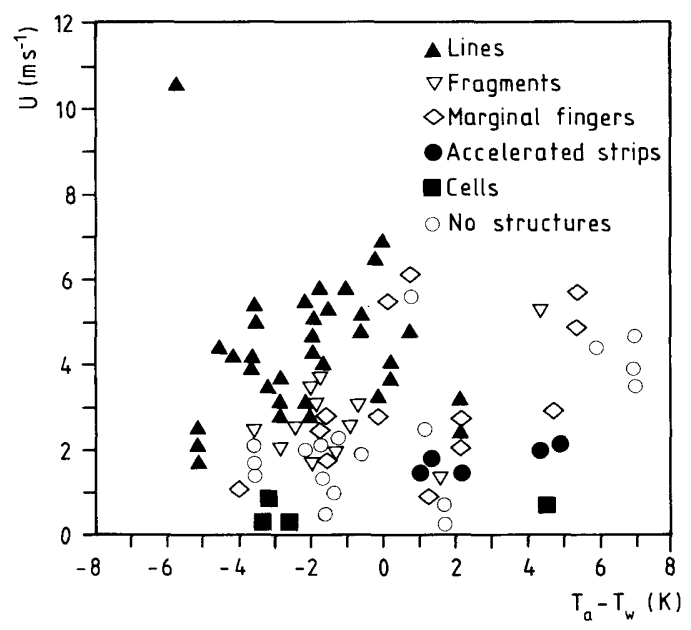

Fig. 5. Observations of secondary flow patterns versus air sea temperature difference and wind speed.

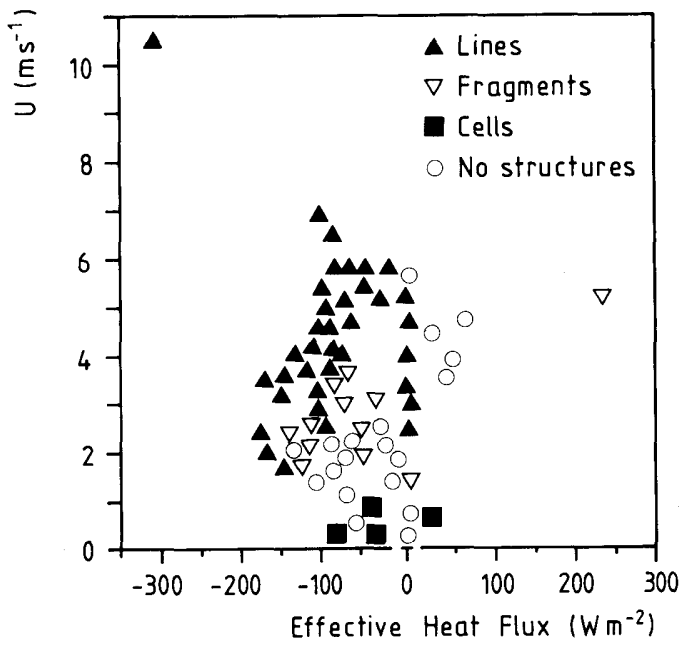

Fig. 6. Observations of secondary flow patterns versus effective heat flux at the surface and wind speed. Effective heat flux is calculated from the sum of latent and sensible heat flux, net longwave radiation, and the amount of shortwave insolation that is absorbed in the uppermost layer.

signatures, especially with changing wind speed or direction. However, because of the small sample, they are not discussed in detail. From wave length $L$ and velocity $v$, we may calculate a characteristic time $t^{*}=L / 2 v$. The average of $t^{*}$ is $1.3 \mathrm{~s}$, and the average wavelength $L$ is $7.6 \mathrm{~cm}$.

The distribution of observations against the typical bulk parameters of air sea interaction is shown in Fig. 5. Although the amount of experimental evidence is limited, the results permit a gross description as follows. Cell-like structures have been observed under calm or near calm conditions only. The different types of elongated structures tend to cluster under different environmental conditions: lines and line fragments dominate in unstable conditions above 2 or $3 \mathrm{~m} / \mathrm{s}$ wind speed. Marginal fingers appear in stable and unstable conditions. "No structures" were confined to below about $2 \mathrm{~m} / \mathrm{s}$ with unstable and to below about $4 \mathrm{~m} / \mathrm{s}$ with stable conditions. It is interesting that accelerated stripes were observed practically in the same area as "no structures", mainly in stable conditions. The border between "lines" and "no structures" is more or less the area of marginal fingers and fragments. Within the natural variation this border also coincides with the threshold wind 

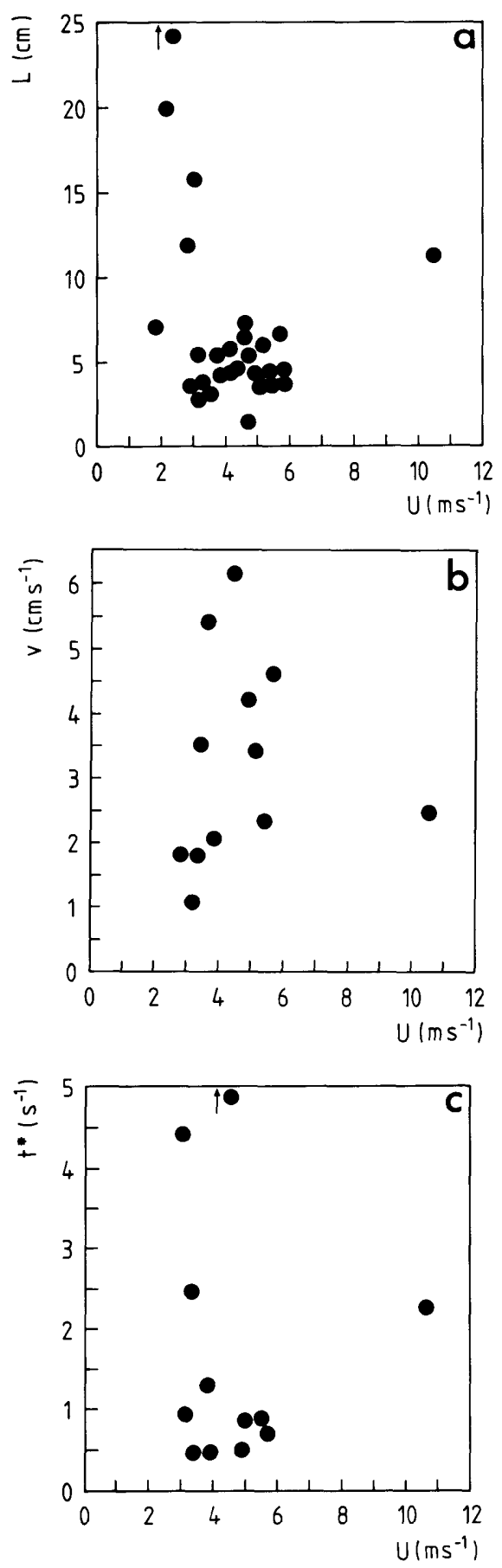

Fig. 7. Relationships between length scale $L$, secondary flow velocity $v$, characteristic time scale $t^{*}$, and wind speed $U$. speed for the appearance of white caps (Monahan and O'Muircheartaigh, 1985).

Fig. 6 is similar to Fig. 5, but in terms of reduced heat flux, that is heat balance at the interface, with only absorption of solar radiation in the uppermost layer considered. The pattern is more clear than in Fig. 5. Again, line structures appear predominately at the unstable side, and require a stability dependent minimum wind speed.

It would be interesting to find a relationship between wave length of line structures, velocity or time scale, and wind speed. Unfortunately with the present sample, it is not possible to derive a relationship that would provide further insight. On the other hand, for those line structures, where a time scale could be derived, the time scale appears to be fairly independent of other parameters (Fig. 7). This makes it reasonable to take this time scale as a typical scale for the secondary motions. Note that the time scale is of order $1 \mathrm{~s}$. This time scale is favourable for surface renewal to be effective in gas exchange.

\section{Conclusion}

The results of the present study show that at the sea surface a variety of small scale surface motions prevail, that indicate surface renewal which because of its short characteristic time scales

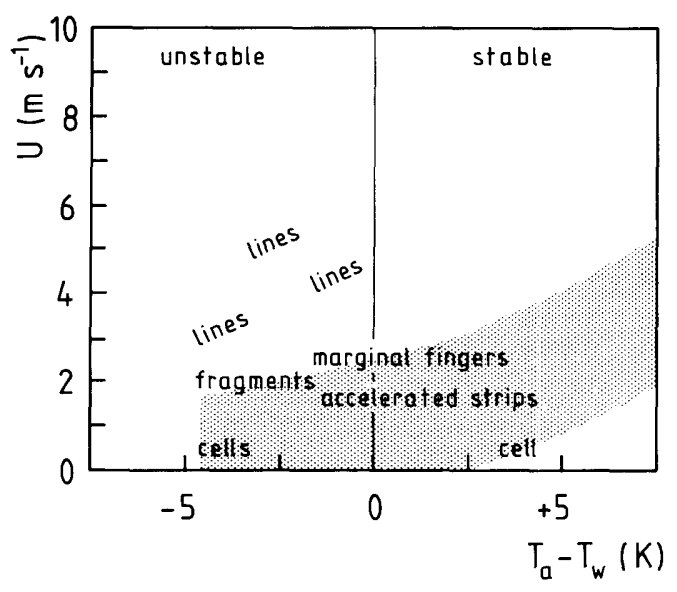

Fig. 8. Typical secondary flow patterns versus air sea temperature difference and wind speed. The shaded area indicates the region where observations with no discernable structures were found. 

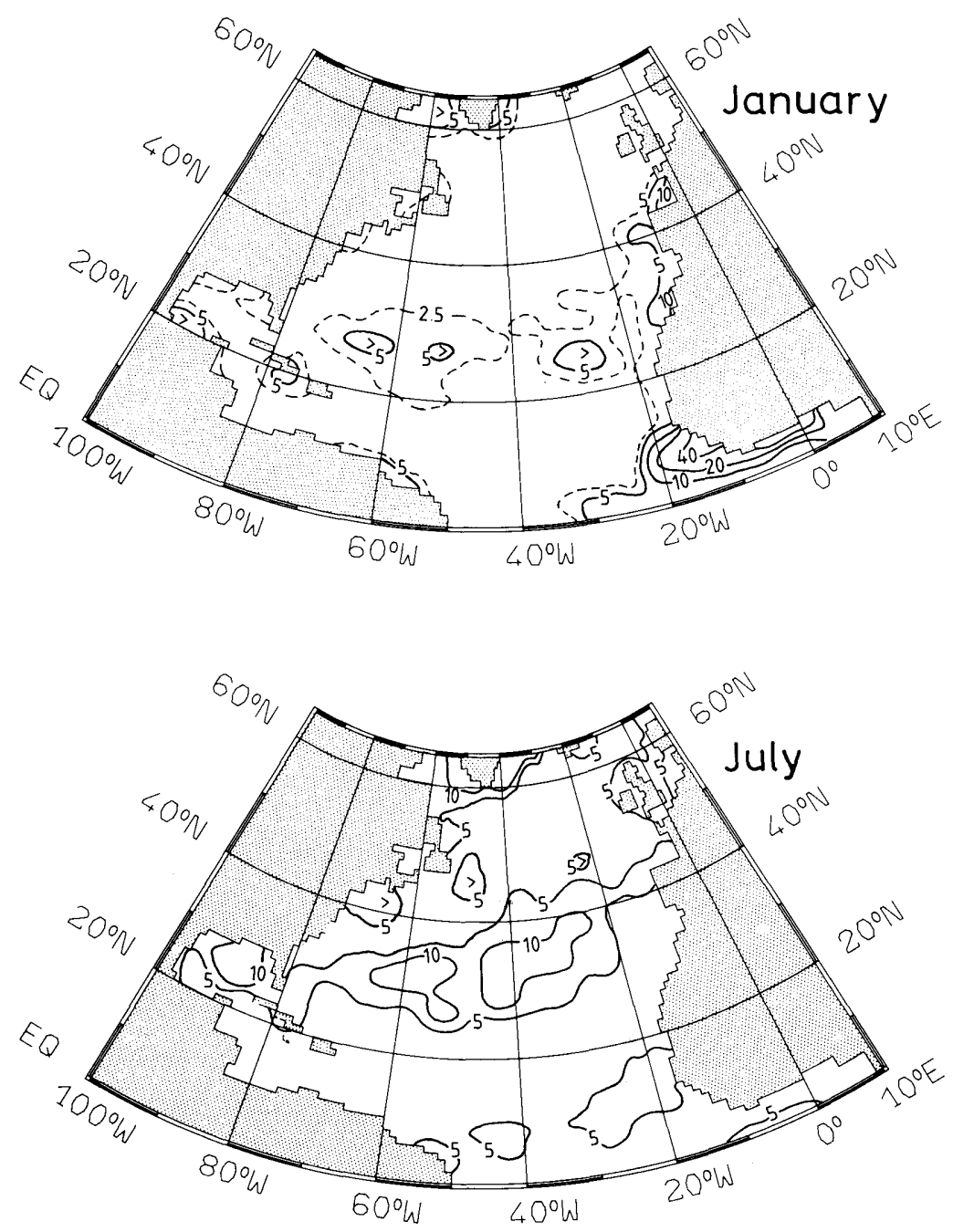

Fig. 9. Frequency of wind speeds not exceeding $2.5 \mathrm{~ms}^{-1}$ at the North Atlantic Ocean in January and July. Reference height for wind is about $25 \mathrm{~m}$. The fields are based on Isemer and Hasse (1987). Frequency is given as a \% observations as indicated at the isolines.

would be favourable for enhancement of gas exchange. In order to estimate the effect of the secondary motions on gas exchange, we would need to calculate a weighted average over the probabilities of the different situations (say in terms of wind speed, conductive and radiative heat fluxes). However, referring to Fig. 8, it appears that situations, where no secondary motions were observed, were mainly confined to low wind speeds. The border line depends on stability, but its stability dependence is small compared to the range of variation of wind speed. Considering that at open sea near neutral or unstable conditions prevail, $2.5 \mathrm{~m} / \mathrm{s}$ can be taken as a rough border between secondary motions and "no structures". Fig. 9 gives the percentage of observations with wind speed below this threshold for the area of the North Atlantic Ocean (Isemer and Hasse, 1987). 
Since the North Atlantic presents a wide range of ocean climate conditions, results for this area can be taken as representative for the world ocean. Our measurements cover the wind speed range up to about $6 \mathrm{~m} / \mathrm{s}$ only. However, it is likely that with increasing wind speeds and wave breaking other types of non-linear processes will give raise to secondary motions. With this in mind we may conclude that except for some areas with frequent calms, in more than $90 \%$ of the time wind speeds are high enough to assume enhancement of gas transfer by secondary motions.

\section{Acknowledgements}

We thank Andreas Kopf for his engagement in the field work, Dr. Kinzer, Kiel for the loan of the video equipment and helpful advice. Figure 9 was kindly produced by Dr. Isemer, Kiel, from the data files. We acknowledge the skilful work of Doris Michaelis and Frauke Nevoigt in the preparing of the manuscript and figures. We also thank our reviewers for their positive action and helpful comments.

\section{REFERENCES}

Asher, W. E. and Pankow, J. F. 1991. Prediction of gas/water mass transport coefficients by a surface renewal model. Environ Sci. Technol. 25, 1294-1300.

Busse, F. H. 1989. Fundamentals of thermal convection. In: Mantle convection (ed. W. R. Peltier). New York: Gordon \& Breach, 23-95.

Coantic, M. 1986. A model of gas transfer across airwater interfaces with capillary waves. J. Geophys. Res. 91, 3925-3943.

Deacon, E. L. 1977. Gas transfer to and across an airwater interface. Tellus 29, 363-374.

Ewing, G. and McAlister, E. D. 1960. On the thermal boundary layer of the ocean. Science 131, 1374-1376.

Gemmrich, J. 1990. Oberflächenerneuerung unter natürlichen Bedingungen. Diplom-Arbeit, Inst. f. Meereskunde, Univ. Kiel, 108 (in German).

Hasse, L. 1971. The sea surface temperature deviation and the heat flow at the sea-air interface. Bound. Lay. Met. 1, 368-379.

Hasse, L. and Liss, P. S. 1980. Gas exchange across the air-sea interface. Tellus 32, 470-481.

Hasse, L. 1990. On the mechanism of gas exchange at the air-sea interface. Tellus 42B, 250-253.

Holmén, K. and Liss, P. 1984. Models for air-water gas transfer: an experimental investigation. Tellus $36 B$, 92-100.

Isemer, H.-J. and Hasse, L. 1987. The Bunker climate atlas of the North Atlantic Ocean, vol. 2. Air-sea interactions. Heidelberg: Springer-Verlag, 252.
Kitaigorodskii, S. A. 1984. On the fluid dynamical theory of turbulent gas transfer across an air-sea interface in the presence of breaking wind-waves. J. Phys. Oceanogr. 14, 960-972.

Krauss, W. 1965. Theorie des Triftstromes und der virtuellen Reibung im Meer. Dt. Hydrogr. Z. 18, 193-210 (in German).

Langmuir, I. 1938. Surface motion of water induced by wind. Science 87, 119-123.

Liu, T. W. and Businger, J. A. 1975. Temperature profile in the molecular sublayer near the surface of a fluid in turbulent motion. Geophys. Res. Letters 2, 403-404.

Monahan, E. and O'Muircheartaigh, I. G. 1986. Whitecaps and the passive remote sensing of the ocean surface. Int. J. Rem. Sensing 7, 627-642.

Monahan, E. C. and MacNiocaill, G. 1986. Oceanic whitecaps and their role in air-sea exchange processes. D. Reidel, Dordrecht, 294.

Phillips, O. M. 1977. The dynamics of the upper ocean. Cambridge Univ. Press. Second edition, 336.

Schmidt, W. 1908. Absorption der Sonnenstrahlung im Wasser. Sitzungsberichte, Akad. Wiss. Wien. 117 (in German).

Woodcock, A. H. 1941. Surface cooling and streaming in shallow fresh and salt waters. J. Marine Res. 4, 153-161. 